\title{
Factorial design analysis for adsorption of dye on activated carbon beads incorporated with calcium alginate
}

\author{
Gurusamy Annadurai ${ }^{\mathrm{a}}$, Ruey-Shin Juang ${ }^{\mathrm{b}, *}$, Duu-Jong Lee ${ }^{\mathrm{a}}$ \\ ${ }^{a}$ Department of Chemical Engineering, National Taiwan University, Taipei 106, Taiwan \\ ${ }^{\mathrm{b}}$ Department of Chemical Engineering, Yuan Ze University, Chung-Li 320, Taiwan
}

\begin{abstract}
Batch adsorption equilibrium of the dye Rhodamine 6G, using activated carbon beads incorporated with calcium alginate (ACCA beads), was studied. The effects of several factors governing the adsorption process, such as dye concentration $(100-300 \mathrm{mg} / \mathrm{l}), \mathrm{pH}(7-9)$, and temperature $\left(30-60^{\circ} \mathrm{C}\right)$, on percent of adsorption were investigated at a fixed dosage of ACCA beads $(1 \mathrm{~g} / \mathrm{l})$. High percentages of adsorption of Rhodamine 6G were obtained using ACCA beads. Based on the analysis of variance and the factorial design of experiments, dye concentration was the most significant factor under the experimental ranges examined. (c) 2002 Elsevier Science Ltd. All rights reserved.
\end{abstract}

Keywords: Factorial design of experiments; Dye adsorption; Activated carbon; Calcium alginate; Incorporation

\section{Introduction}

Textile and tannery effluents are two of the most polluting industrial wastes, and the problems of treatment and disposal of such wastes require much attention. It is difficult to remove the dyes from the effluents, since most dyes are stable to light and heat and are not biodegradable (McKay, 1982). Thus, the common methods for color removal, including primary and secondary treatment processes applied in sewage plants, are unsuitable (McKay et al., 1986; Nassar and ElGeundi, 1991). Rates of treatment of dyes are generally low, and untreated dyes may have a serious impact on

\footnotetext{
* Corresponding author. Department of Chemical Engineering, Yuan Ze University, Chung-Li 320, Taiwan; Tel.: +886-3-4636800 ext. 555; fax: +886-3-4559373.

E-mail address: cejuang@ce.yzu.edu.tw (R. Juang).
}

receiving water. The adsorption process has been considered because it has the ability to treat dyes in more concentrated form (Annadurai et al., 1999a).

Activated carbons (granular or powder) are widely used adsorbents owing to their excellent adsorption abilities for a vast number of organic compounds. However, steam regeneration is energy consuming and the price of the adsorbents is relatively high, which limits their usage (El-Geundi, 1997). In practice, many workers have searched for cheaper substitutes made from natural resources. Fly ash, agricultural wastes (coconut shell, rice husk, etc.), seafood wastes (chitin, chitosan, etc.), and natural polymers such as alginate have been tested for color removal (El-Geundi, 1997; Juang et al., 1997; Khare et al., 1987; Mall and Upadhyay, 1995; Yang and Zall, 1984).

On the other hand, the potential of co-immobilized systems utilizing entrapped materials such as living cells has been recognized in several water treatment 
and fermentation processes (Lin and Chen, 1995; Murata et al., 1993; Pai et al., 1995). The use of such techniques in wastewater treatment offers a promising way of improving the efficiency of the adsorption process, especially in solving the problems associated with solid-liquid separation in settling tanks (Hashimoto and Furukawa, 1987). In our laboratory, a series of experiments has been conducted to evaluate the performance of activated carbon incorporated with calcium alginate for adsorption of organic matter. The immobilization of living cells on activated carbons by adsorption, or in alginate by entrapment, has often been used in biological applications (Lin and Chen, 1995; Murata et al., 1993; Pai et al., 1995). To our best knowledge, however, little attention has been paid to the environmental applications of this type of adsorbent. This paper first illustrates the use of variance analysis and factorial design of experiments to provide insight into the adsorption process (Jose, 1987; Liposan and Sheth, 1973; Yates, 1937). That is, the significance of the effect of three main experimental variables (dye concentration, temperature and $\mathrm{pH}$ ) on the percent of dye adsorption was identified.

\section{Mathematical model}

In the factorial design of experiments, when responses and input variables (factors), initial dye concentration and temperature are continuous, it is useful to consider the factor-response relationship in terms of a mathematical model. For qualitative factors where there is no continuous link between the response and the levels of a factor, it is necessary to consider a comparison of response between two levels of a qualitative factor. In this work, initial solution $\mathrm{pH}$ with two levels is examined (Jose, 1987). The factorial approach will result in a considerable saving of time and materials devoted to the experiments. First, the factor that is independent of all simple effects of a factor is equal to its main effect. The consequences of variations in the factors and the main effects are the only quantities that need to be stated. Second, each main effect in the factorial experiments is estimated with the same accuracy as if the whole experiment had been devoted to the factor alone (Yates, 1937). Thus, the advantages of this method are: (1) all experimental units are used in evaluating effects, resulting in the most efficient use of resources; (2) the effects are evaluated over a wider range of conditions with the minimum of resources; (3) a factorial set of treatments is optimized for estimating main effects and interactions.

In this work, factorial design experiments are used in the analysis of adsorption of dye. Three input variables, dye concentration, temperature and $\mathrm{pH}$, are considered. It is useful to consider the factor response relationship in terms of a mathematical model such as the response function. The use of variance analysis and factorial design of experiments allows us to express the percent of adsorption as a polynomial model. If the levels of the factors are equally spaced, the orthogonal polynomial adopted to give a more detailed equation for the response will be:

$$
\begin{aligned}
Y= & b_{0}+b_{1} C+b_{2} T+b_{3} P+b_{4} C^{2}+b_{5} T^{2} \\
& +b_{6} C T+b_{7} C P+b_{8} T P+b_{9} C T P+b_{10} C^{2} T \\
& +b_{11} C^{2} P+b_{12} C T^{2}+b_{13} T^{2} P+b_{14} C^{2} T^{2} \\
& +b_{15} C^{2} T P+b_{16} C T^{2} P+b_{17} C^{2} T^{2} P
\end{aligned}
$$

where $Y=$ predicted response (percent of dye adsorption), $b_{i}=$ coefficients of polynomial equation, $C=$ initial dye concentration $(\mathrm{mg} / \mathrm{l}), T=$ temperature $\left({ }^{\circ} \mathrm{C}\right)$ and $P=$ initial $\mathrm{pH}$.

The method used for calculation of the effects and their sums of squares, as we will see below, is a simple extension of the method introduced by Yates for a $2^{n}$ factorial design (Jose, 1987; Yates, 1937). The main and interaction effects are all linear combinations of the observations. A convenient way of estimating these effects for a $3^{3} \times 2^{1}$ factorial design is to establish a table of the appropriate multipliers that are applied to the observations. Table 1 lists the coefficients of this design. Furthermore, the analysis of variance permits us to eliminate the terms in Eq. (1) that are insignificant at a specified level of confidence.

\section{Experimental}

\subsection{Materials}

Sodium alginate from brown algae was purchased as alginic acid sodium salt (Fluka Co.). Powdered activated carbon was supplied by Merck Co. and used as received. It had an average particle diameter of 0.55 $\mathrm{mm}$. The BET surface area, mean pore size, and total pore volume of activated carbon were measured to be $726 \mathrm{~m}^{2} / \mathrm{g}, 2.4 \mathrm{~nm}$, and $0.435 \mathrm{~cm}^{3} / \mathrm{g}$, respectively, from $\mathrm{N}_{2}$ isotherms using a sorptiometer (Porous Materials Inc., BET-202A). The dye Rhodamine 6G (C.I. 45160, Basic Red 1, and formal weight 479.0) was purchased from Sigma Co., and was used without further purification. The aqueous solution was prepared by dissolving dye in deionized water (Millipore, Mill-Q). The initial $\mathrm{pH}$ value was adjusted by adding a small amount of $\mathrm{HNO}_{3}$ or $\mathrm{NaOH}$. 
Table 1

Multipliers for derivation of the effects in a $3^{3} 2^{1}$ factorial design (Yates, 1937)

\begin{tabular}{|c|c|c|c|c|c|c|c|c|c|c|c|c|c|c|c|c|c|c|c|}
\hline Run & 1 & 2 & 3 & 4 & 5 & 6 & 7 & 8 & 9 & 10 & 11 & 12 & 13 & 14 & 15 & 16 & 17 & 18 & $\operatorname{DSS}^{\mathrm{a}}$ \\
\hline \multicolumn{20}{|l|}{$M \cdot E^{\mathrm{a}}$} \\
\hline $\mathrm{C}_{1}$ & -1 & 0 & 1 & -1 & 0 & 1 & -1 & 0 & 1 & -1 & 0 & 1 & -1 & 0 & 1 & -1 & 0 & 1 & $12 \mathrm{r}$ \\
\hline $\mathrm{C}_{2}$ & 1 & -2 & 1 & 1 & -2 & 1 & 1 & -2 & 1 & 1 & -2 & 1 & 1 & -2 & 1 & 1 & -2 & 1 & $36 \mathrm{r}$ \\
\hline $\mathrm{T}_{1}$ & 1 & 1 & 1 & 0 & 0 & 0 & -1 & -1 & -1 & 1 & 1 & 1 & 0 & 0 & 0 & -1 & -1 & -1 & $12 \mathrm{r}$ \\
\hline $\mathrm{T}_{2}$ & 1 & 1 & 1 & -2 & -2 & -2 & 1 & 1 & 1 & 1 & 1 & 1 & -2 & -2 & -2 & 1 & 1 & 1 & $36 \mathrm{r}$ \\
\hline $\begin{array}{l}\mathrm{P}_{1} \\
\text { I. E. }\end{array}$ & 1 & 1 & 1 & 1 & 1 & 1 & 1 & 1 & 1 & -1 & -1 & -1 & -1 & -1 & -1 & -1 & -1 & -1 & $18 \mathrm{r}$ \\
\hline $\mathrm{C}_{1} \mathrm{~T}_{1}$ & -1 & 0 & 1 & 0 & 0 & 0 & 1 & 0 & -1 & -1 & 0 & 1 & 0 & 0 & 0 & 1 & 0 & -1 & $8 \mathrm{r}$ \\
\hline $\mathrm{C}_{1} \mathrm{P}_{1}$ & -1 & 0 & 1 & -1 & 0 & 1 & -1 & 0 & 1 & 1 & 0 & -1 & 1 & 0 & -1 & 1 & 0 & -1 & $12 r$ \\
\hline $\mathrm{T}_{1} \mathrm{P}_{1}$ & 1 & 1 & 1 & 0 & 0 & 0 & -1 & -1 & -1 & -1 & -1 & -1 & 0 & 0 & 0 & 1 & 1 & 1 & $12 r$ \\
\hline $\mathrm{C}_{1} \mathrm{~T}_{2}$ & -1 & 0 & 1 & 2 & 0 & -2 & -1 & 0 & 1 & -1 & 0 & 1 & 2 & 0 & -2 & -1 & 0 & 1 & $24 \mathrm{r}$ \\
\hline $\mathrm{C}_{2} \mathrm{~T}_{1}$ & 1 & -2 & 1 & 0 & 0 & 0 & -1 & 2 & -1 & 1 & -2 & 1 & 0 & 0 & 0 & -1 & 2 & -1 & $24 \mathrm{r}$ \\
\hline $\mathrm{C}_{2} \mathrm{P}_{1}$ & 1 & -2 & 1 & 1 & -2 & 1 & 1 & -2 & 1 & -1 & 2 & -1 & -1 & 2 & -1 & -1 & 2 & -1 & $36 r$ \\
\hline $\mathrm{C}_{2} \mathrm{~T}_{2}$ & 1 & -2 & 1 & -2 & 4 & -2 & 1 & -2 & 1 & 1 & -2 & 1 & -2 & 4 & -2 & 1 & -2 & 1 & $72 \mathrm{r}$ \\
\hline $\mathrm{T}_{2} \mathrm{P}_{1}$ & 1 & 1 & 1 & -2 & -2 & -2 & 1 & 1 & 1 & -1 & -1 & -1 & 2 & 2 & 2 & -1 & -1 & -1 & $36 r$ \\
\hline $\mathrm{C}_{1} \mathrm{~T}_{1} \mathrm{P}_{1}$ & -1 & 0 & 1 & 0 & 0 & 0 & 1 & 0 & -1 & 1 & 0 & -1 & 0 & 0 & 0 & -1 & 0 & 1 & $8 \mathrm{r}$ \\
\hline $\mathrm{C}_{1} \mathrm{~T}_{2} \mathrm{P}_{1}$ & -1 & 0 & 1 & 2 & 0 & -2 & -1 & 0 & 1 & 1 & 0 & -1 & -2 & 0 & 2 & 1 & 0 & -1 & $24 \mathrm{r}$ \\
\hline $\mathrm{C}_{2} \mathrm{~T}_{1} \mathrm{P}_{1}$ & 1 & -2 & 1 & 0 & 0 & 0 & -1 & 2 & -1 & -1 & 2 & -1 & 0 & 0 & 0 & 1 & -2 & 1 & $24 \mathrm{r}$ \\
\hline $\mathrm{C}_{2} \mathrm{~T}_{2} \mathrm{P}_{1}$ & 1 & -2 & 1 & -2 & 4 & -2 & 1 & -2 & 1 & -1 & 2 & -1 & 2 & -4 & 2 & -1 & 2 & -1 & $72 \mathrm{r}$ \\
\hline
\end{tabular}

${ }^{\mathrm{a}}$ M.E. $=$ main effects, I.E. $=$ interaction effects, DSS = division for sum of squares. 


\subsection{Preparation of ACCA beads}

Sodium alginate was dissolved in a solution containing the material to be encapsulated. The final alginate concentration was $2 \%(\mathrm{w} / \mathrm{v})$, to which $1 \%(\mathrm{w} / \mathrm{v})$ activated carbon was added. The viscous solution was introduced into a $100-\mathrm{cm}^{3}$ burette and extruded through a nozzle with $0.16-\mathrm{mm}$ diameter. The droplets were pulled off on $200 \mathrm{~cm}^{3}$ of a $0.05-\mathrm{mol} / 1 \mathrm{CaCl}_{2}$ stirred solution. After allowing the beads ( $3 \mathrm{~mm}$ in size) to harden for $1 \mathrm{~h}$, they were rinsed with deionized water and then transferred into $75 \mathrm{~cm}^{3}$ of deionized water for storage at $4^{\circ} \mathrm{C}$.

\subsection{Batch equilibrium and design of experiments}

Batch adsorption equilibrium was determined in solutions containing a dosage of ACCA beads $(1 \mathrm{~g} / \mathrm{l})$ and different dye concentrations (100, 200 and $300 \mathrm{mg} / \mathrm{l})$, initial $\mathrm{pH}$ values (7, 8 and 9$)$, and temperatures $(30,45$ and $60^{\circ} \mathrm{C}$ ) in conical flasks. The conical flasks were shaken at $180 \mathrm{rev} . / \mathrm{min}$ for 4 days in a water bath (Firstek B603, Taiwan). The final concentration of dye in the aqueous solutions was analyzed using a Hitachi UV/visible spectrophotometer (Model U2000) at 528 $\mathrm{nm}$. Each experiment was at least duplicated under identical conditions. Reproducibility of the equilibrium measurements was within $4 \%$ (mostly $2 \%$ ).

The ranges of the three independent variables used in the design of the experiments were the same as those used in the batch adsorption equilibrium experiments, except that only two levels of temperatures were selected $\left(30\right.$ and $\left.60^{\circ} \mathrm{C}\right)$. The dye concentration, $\mathrm{pH}$ and temperature used in the 18 experiments are listed in Table 2.

\subsection{Scanning electron microscopy of ACCA beads}

The dye adsorbed onto the ACCA beads was fixed with $2.0 \% \mathrm{w} / \mathrm{v}$ glutaraldehyde overnight. The sample was dehydrated by sequential immersion for $30 \mathrm{~min}$ by increasing concentrations of acetone $(20,30,60,80$ and $90 \% \mathrm{w} / \mathrm{v}$, and anhydrous acetone). The dehydrated beads were dried and covered with a thin layer of gold. The surface structure of the beads was observed using a scanning electron microscope (JEOL Japan, Model JSM-5600) operated at $15 \mathrm{kV}$.

\section{Results and discussion}

The adsorption capacity is one of the essential parameters in the process design of a specific adsorbate-adsorbent system. Figs. 1 and 2 show the effect of temperature, initial $\mathrm{pH}$, and dye concentration on the
Table 2

Operating conditions

\begin{tabular}{rlll}
\hline Trial no. & $\begin{array}{l}\text { Dye concen- } \\
\text { tration } \\
(\mathrm{mg} / \mathrm{l})\end{array}$ & $\mathrm{pH}$ & $\begin{array}{l}\text { Tempera- } \\
\text { ture } \\
\left({ }^{\circ} \mathrm{C}\right)\end{array}$ \\
\hline 1 & 100 & 7 & 30 \\
2 & 200 & 7 & 30 \\
3 & 300 & 7 & 30 \\
4 & 100 & 8 & 30 \\
5 & 200 & 8 & 30 \\
6 & 300 & 8 & 30 \\
7 & 100 & 9 & 30 \\
8 & 200 & 9 & 30 \\
9 & 300 & 9 & 30 \\
10 & 100 & 7 & 60 \\
11 & 200 & 7 & 60 \\
12 & 300 & 7 & 60 \\
13 & 100 & 8 & 60 \\
14 & 200 & 8 & 60 \\
15 & 300 & 8 & 60 \\
16 & 100 & 9 & 60 \\
17 & 200 & 9 & 60 \\
18 & 300 & 9 & 60 \\
\hline
\end{tabular}

percent of adsorption. It is evident that the ACCA beads have a good capability for adsorption of the dye Rhodamine 6G. In addition, the percent of adsorption



Fig. 1. Percent of dye adsorption at different temperatures and dye concentrations. The dosage of ACCA beads is $1 \mathrm{~g} / 1$. 


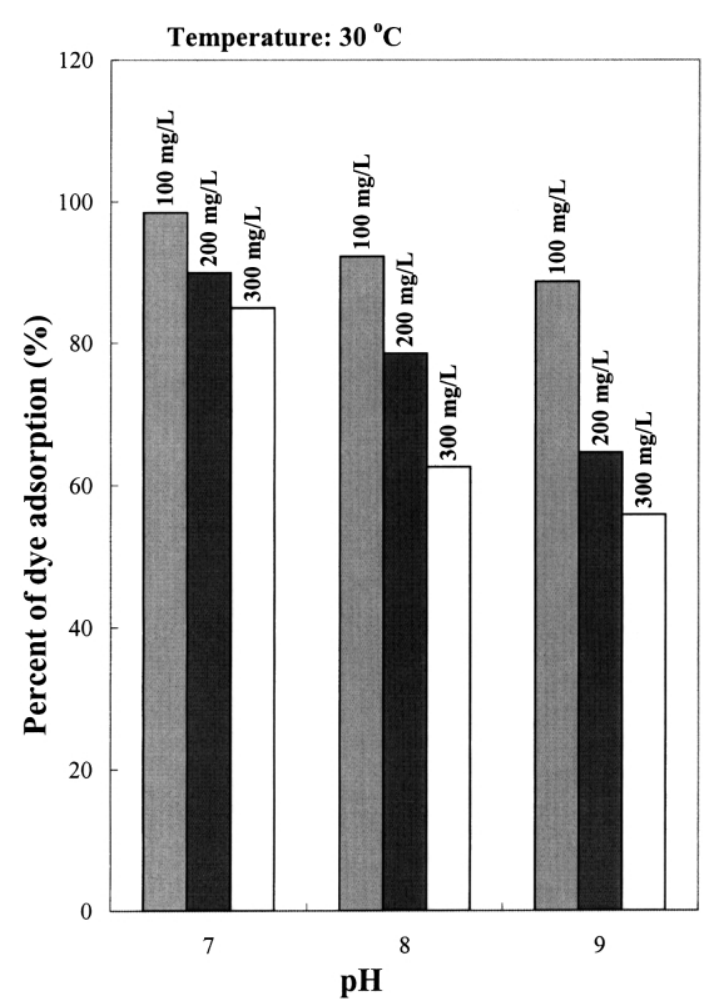

Fig. 2. Percent of dye adsorption at different initial $\mathrm{pH}$ values and dye concentrations. The dosage of ACCA beads is $1 \mathrm{~g} / 1$.

increased when the temperature increased from 30 to $60^{\circ} \mathrm{C}$ (Fig. 1), but decreased with increasing dye concentration or initial $\mathrm{pH}$ (Fig. 2). It appears from the experimental results that the effect of temperature is comparatively smaller. This implies that the present adsorption process is physical in nature. An increase in temperature would slightly increase the diffusivity of large dye molecules or ions and also produce a swelling effect within the internal structure of the ACCA beads. This would enable the dye molecules or ions to penetrate further (Annadurai et al., 1999b; Asfour et al., 1985; McKay, 1982). The possibility that more of the higher-capacity activated carbon was exposed at higher temperatures, perhaps as a result of dissolution of the lower-capacity alginate (Murata et al., 1993), was also considered. However, based on the measurements of calcium concentration in the aqueous phase, this was not the case.

It is known that many biopolymers such as sodium/calcium alginate, glutaraldehyde and agarose can sorb organic matter and strongly bind heavy metal ions (Aksu et al., 1999). They are non-toxic, efficient and cheap, and thus highly competitive with activated carbon or polymeric resins. The adsorption capacity of the ACCA beads for Rhodamine $6 \mathrm{G}$ was generally found to be lower than that of common activated carbons (Murata et al., 1993). However, the ACCA beads are more suitably used as immobilization supports for bacteria or fungus. This can improve biomass performance and biosorption capacity, which is promising for microbiological degradation of organic pollutants (Aksu et al., 1999; Zhang and Yu, 2000).

Three levels of initial dye concentrations and $\mathrm{pH}$ values, and two levels of temperatures were selected for factorial design of experiments according to the method by Yates (1937). A total of 18 experiments (Table 2) were used for error estimation of the threefactor linear and quadratic interactions. The main and interaction effects obtained were multiplied by appropriate coefficients as shown in Table 1 . The measured and predicted data are listed in Table 3, revealing a reasonably good agreement.

The results of variance analysis with linear terms and quadratic terms for each run are also listed in Table 4. (The subscript 1 indicates linear terms and the subscript 2 indicates quadratic terms.) The significance effect of each term (the fifth column) and the significance levels through the $F$-distribution (the last column) are calculated. In general, the linear terms are more significant than the quadratic interactions. It is shown that the dye concentration is the most significant factor and temperature is the most insignificant one in the present adsorption process (Jose, 1987; Liposan and Sheth, 1973). This confirms the experimental observations as indicated above. The solution $\mathrm{pH}$ has little effect in this case, as has been previously reported in adsorption of dyes and organic matter using activated carbons (McKay, 1982; McKay et al., 1986; Namasivayam and Arsi, 1997). Furthermore, the analysis

Table 3

Actual and predicted percents for dye adsorption

\begin{tabular}{lcc}
\hline Trial no. & $\begin{array}{l}\text { Actual value } \\
(\%)\end{array}$ & $\begin{array}{l}\text { Predicted value } \\
(\%)\end{array}$ \\
\hline 1 & 98.50 & 98.47 \\
2 & 96.70 & 96.77 \\
3 & 94.80 & 95.07 \\
4 & 98.70 & 98.71 \\
5 & 97.00 & 97.01 \\
6 & 95.30 & 95.31 \\
7 & 99.20 & 98.95 \\
8 & 97.30 & 97.25 \\
9 & 95.60 & 95.55 \\
10 & 99.90 & 99.80 \\
11 & 98.20 & 98.10 \\
12 & 96.40 & 96.40 \\
13 & 100.0 & 100.04 \\
14 & 98.60 & 98.34 \\
15 & 96.70 & 96.64 \\
16 & 100.0 & 100.02 \\
17 & 98.20 & 98.59 \\
18 & 97.10 & 96.89 \\
\hline
\end{tabular}


Table 4

Analysis of variance

\begin{tabular}{|c|c|c|c|c|c|c|}
\hline Run & Observation & $\begin{array}{l}\text { Degree of } \\
\text { freedom }\end{array}$ & $\begin{array}{l}\text { Division for } \\
\text { sum of squares }\end{array}$ & $\begin{array}{l}\text { Significance } \\
\text { effect }\end{array}$ & $\begin{array}{l}\text { Variance } \\
\text { relation }\end{array}$ & $\begin{array}{l}\text { Significance } \\
\text { level }\end{array}$ \\
\hline $\mathrm{C}_{1}$ & -20 & 1 & 12 & 33.33 & 537.58 & $99 \%^{\mathrm{a}}, 95 \%^{\mathrm{b}}$ \\
\hline $\mathrm{C}_{2}$ & 0 & 1 & 36 & - & - & \\
\hline $\mathrm{T}_{1}$ & -2.90 & 1 & 12 & 0.233 & 3.3758 & $95 \%^{\mathrm{b}}$ \\
\hline $\mathrm{T}_{2}$ & 0 & 1 & 36 & - & - & \\
\hline $\mathrm{P}_{1}$ & -11.80 & 1 & 18 & 7.73 & 124.67 & $99 \%^{\mathrm{a}}, 95 \%^{\mathrm{b}}$ \\
\hline $\mathrm{C}_{1} \mathrm{~T}_{1}$ & -0.7 & 1 & 8 & 0.061 & 0.9870 & \\
\hline $\mathrm{C}_{1} \mathrm{P}_{1}$ & -1.5 & 1 & 12 & 0.187 & 3.024 & $95 \%^{\mathrm{b}}$ \\
\hline $\mathrm{T}_{1} \mathrm{P}_{1}$ & -1.3 & 1 & 12 & 0.140 & 2.2709 & $95 \%^{\mathrm{b}}$ \\
\hline $\mathrm{C}_{1} \mathrm{~T}_{2}$ & -0.3 & 1 & 24 & 0.037 & - & \\
\hline $\mathrm{C}_{2} \mathrm{~T}_{1}$ & -1.1 & 1 & 24 & 0.050 & - & \\
\hline $\mathrm{C}_{2} \mathrm{P}_{1}$ & 0 & 1 & 36 & - & - & \\
\hline $\mathrm{C}_{2} \mathrm{~T}_{2}$ & 0 & 1 & 72 & - & - & \\
\hline $\mathrm{T}_{2} \mathrm{P}_{1}$ & 0.9 & 1 & 36 & 0.022 & - & \\
\hline $\mathrm{C}_{1} \mathrm{~T}_{1} \mathrm{P}_{1}$ & 0.5 & 1 & 8 & 0.031 & - & \\
\hline $\mathrm{C}_{1} \mathrm{~T}_{2} \mathrm{P}_{1}$ & 0.7 & 1 & 24 & 0.020 & - & \\
\hline $\mathrm{C}_{2} \mathrm{~T}_{1} \mathrm{P}_{1}$ & 0.5 & 1 & 24 & 0.010 & - & \\
\hline $\mathrm{C}_{2} \mathrm{~T}_{2} \mathrm{P}_{1}$ & 1.5 & 1 & 72 & 0.031 & - & \\
\hline
\end{tabular}

of variance (Table 5) indicates that the orthogonal polynomial equation [Eq. (1)] can be satisfactorily used in such multiple linear regression analysis ( $F$-value, 396.73; $R^{2}$-value, 0.9884).

It should be noted that the model parameters [Eq. (1)] were determined by an ANOVA fitting exercise so that the model could adequately correlate most of the data. The model is then used to 'predict' the remaining data, e.g. the measurement made at $45^{\circ} \mathrm{C}$. In other words, this model is essentially predictive, rather than correlative.

Finally, the surface structures of the ACCA beads before and after dye adsorption are shown in Fig. 3. The SEM photographs of the fresh ACCA beads illustrate that the whole beads have a smooth surface with compact structure (Fig. 3a,b). The original 'color' monitor images (Fig. 3c-h) clearly show that the dye Rhodamine $6 \mathrm{G}$ is homogeneously adsorbed on the surfaces of the ACCA beads at different initial dye concentrations $(100,200$ and $300 \mathrm{mg} / \mathrm{l})$. It is noted that these color figures are available from the authors. The present results indicate the possibility of using the ACCA beads for adsorption of dyes from aqueous streams.

\section{Conclusions}

The factorial design of experiments for batch adsorption of the dye Rhodamine $6 \mathrm{G}$ using activated carbon beads incorporated with calcium alginate (ACCA beads) was studied. The effects of three factors (initial dye concentration $(100-300 \mathrm{mg} / \mathrm{l})$, initial $\mathrm{pH}$ (7-9), and temperature $\left(30-60^{\circ} \mathrm{C}\right)$ ) on percent of adsorption were identified. The statistical analysis for each case confirmed that the orthogonal polynomial equation [Eq. (1)] gave a reasonably good fit with an $F$-value of 396.73 and an $R^{2}$-value of 0.9884 . According to the significance effect obtained in variance analysis, the initial dye concentration was the most significant

Table 5

Regression analysis for adsorption of dye by linear model fitting (ANOVA)

\begin{tabular}{lccccc}
\hline Source & Sum of squares & d.f. & Mean square & $F$-value & $P>F$ \\
\hline Model & 43.38 & 3 & 14.46 & 396.73 & $<0.0001$ \\
Residual & 0.51 & 14 & 0.036 & & \\
Core total & 43.89 & 17 & & \\
& $R^{2}=0.9884$ & & & \\
\hline
\end{tabular}




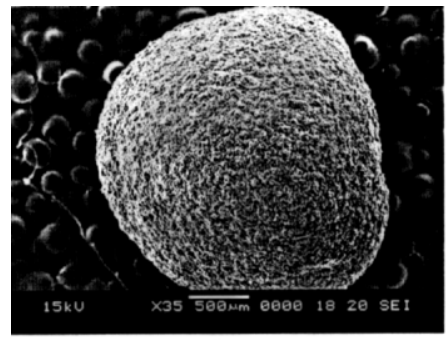

(a)

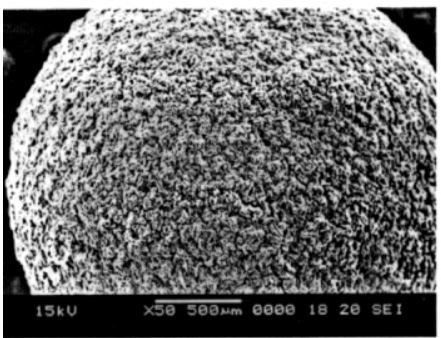

(c)

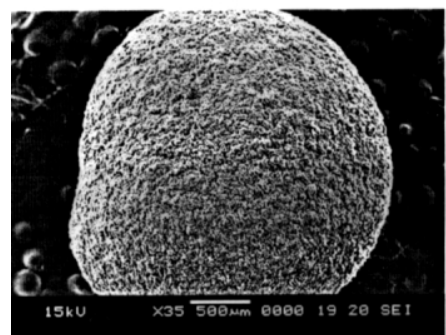

(e)

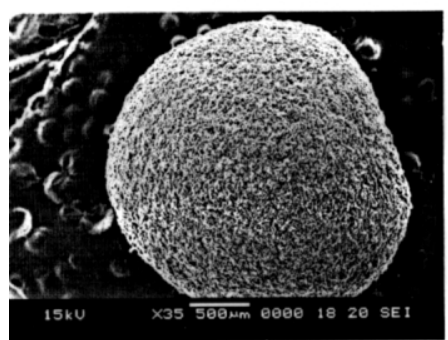

(g)

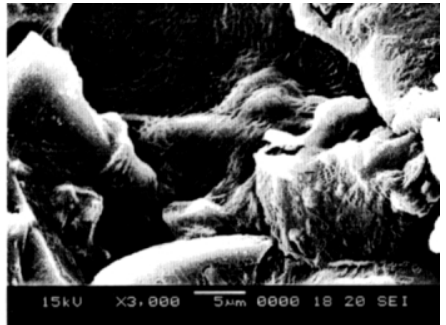

(b)

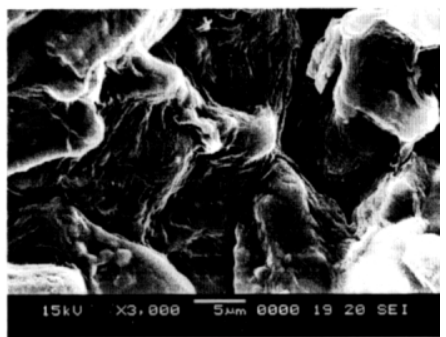

(d)

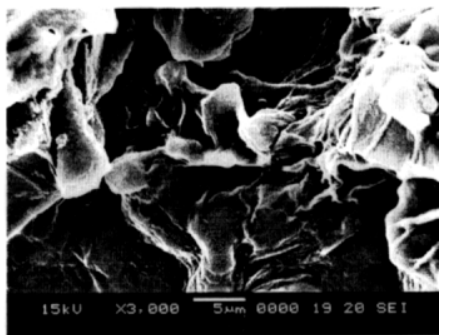

(f)



(h)

Fig. 3. Scanning electron micrographs of the ACCA beads. Fresh beads, (3a,b); after adsorption at $\mathrm{pH} 7$ and $30^{\circ} \mathrm{C}$ with dye concentration of 100 (3c,d), 200 (3e,f), and $300 \mathrm{mg} / 1$ (3g,h).

factor in this process and temperature was the most insignificant factor under the conditions investigated.

\section{Acknowledgements}

Financial support for this work by the National Science Council of ROC under Grant No. NSC89-2211-E002-008 is gratefully appreciated.

\section{References}

Aksu, Z., Egretli, G., Kutsal, T., 1999. A comparative study for the biosorption characteristics of chromium(VI) on Ca-alginate, agarose and immobilized $C$. vulgaris in a continuous packed bed column. J. Environ. Sci. Health A34, 295-316.

Annadurai, G., Mahesh, K.P.O., Murugesh, P., Vasanthakumar, R., 1999a. Response surface method for experimental optimization for adsorption of basic dye on chelating polymer. Asian J. Microbiol. Environ. Sci. 1, 85-91.

Annadurai, G., Chellapandian, M., Krishnan, M.R.V., 1999b. 
Adsorption of reactive dye on chitin. Environ. Monit. Assess. 59, 111-119.

Asfour, H.M., Fadeli, O.A., Nasser, M.M., El-Geundi, M.S., 1985. Equilibrium studies on adsorption of basic dyes on hard wood. J. Chem. Technol. Biotechnol. 35A, 21-27.

El-Geundi, M.S., 1997. Adsorbents for industrial pollution control. Adsorpt. Sci. Technol. 15, 777-787.

Hashimoto, S., Furukawa, K., 1987. Immobilization of activated sludge by PVA-boric acid method. Biotechnol. Bioeng. 30, 52-59.

Jose, A., 1987. Use of factorial design of experiments in the determination of adsorption equilibrium constants. Methyl iodide in charcoals. J. Chem. Technol. Biotechnol. 38, 143-151.

Juang, R.S., Tseng, R.L., Wu, F.C., Lee, S.H., 1997. Adsorption behavior of reactive dyes from aqueous solutions on chitosan. J. Chem. Technol. Biotechnol. 70, 391-399.

Khare, J.K., Panday, K.K., Srivastava, R.M., Singh, V.N., 1987. Removal of Victoria Blue from aqueous solution by fly ash. J. Chem. Technol. Biotechnol. 38, 99-101.

Lin, Y.F., Chen, K.C., 1995. Denitrification and methanogenesis in a co-immobilized mixed culture system. Water Res. $29,35-43$.

Liposan, D., Sheth, J., 1973. Statistical Design and Analysis of Engineering Experiments, Chapter 6. McGraw-Hill, New York.

Mall, I.D., Upadhyay, S.N., 1995. Removal of basic dyes from wastewater using boiler bottom ash. Indian J. Environ. Health 37, 1-10.

McKay, G., 1982. Adsorption of dyestuffs from aqueous solu- tions with activated carbon. I. Equilibrium and batch contact-time studies. J. Chem. Technol. Biotechnol. 32, 759-772.

McKay, G., Prasad, G.R., Mouli, P.R., 1986. Equilibrium studies for the adsorption of dyestuff from aqueous solutions by low cost materials. Water Air Soil Pollut. 29, 273-276.

Murata, Y., Nakada, K., Miyamoto, E., Kawashima, S., Seo, S.H., 1993. Influence of erosion of calcium-induced alginate gel matrix on the release of Brilliant Blue. J. Control. Release 23, 21-26.

Namasivayam, C., Arsi, D.J.S.E., 1997. Removal of Congo Red from wastewater by adsorption onto waste red mud. Chemosphere 34, 401-417.

Nassar, M.M., El-Geundi, M.S., 1991. Comparative cost of color removal from textile effluents using natural adsorbents. J. Chem. Technol. Biotechnol. 50, 257-262.

Pai, S.L., Hsu, Y.L., Chong, N.M., Sheu, C.S., Chen, C.H., 1995. Continuous degradation of phenol by Rhodococcus sp. immobilized on granular activated carbon and calcium alginate. Biores. Technol. 51, 37-42.

Yang, T.C., Zall, R.R., 1984. Adsorption of metals by natural polymers generated from seafood processing wastes. Ind. Eng. Chem. Prod. Res. Dev. 23, 168-171.

Yates, F., 1937. The Design and Analysis of Factorial Experiments. Imperial Bureau of Soil Science, Harpenden.

Zhang, F., Yu, J., 2000. Decolorization of Acid Violet 7 with complex pellets of white rot fungus and activated carbon. Bioproc. Eng. 23, 295-301. 